\title{
TREATMENT OF NATURALLY ACQUIRED DEMODECTIC MANGE WITH AMITRAZ IN TWO HARBOUR SEALS (PHOCA VITULINA)
}

\author{
Kyoo-Tae KIM ${ }^{1}$, Seung-Hun $\mathrm{LEE}^{2}$ and Dongmi KWAK ${ }^{2 *}$ \\ ${ }^{1}$ Animal Health Center of Zoo Land, Daejeon O-World Theme Park, Jung-gu, Daejeon, \\ Korea; ${ }^{2}$ College of Veterinary Medicine, Kyungpook National University, 80 Daehakro, \\ Buk-gu, Daegu 702-701, Korea
}

(Received 3 April 2015; accepted 22 June 2015)

\begin{abstract}
Two male harbour seals (Phoca vitulina; 33 and 35 years old, respectively), housed since 2002 at a zoo for exhibition purposes, developed severe, multifocal and diffuse skin lesions. Skin scrapings and microscopy for parasites as well as pure cultures for bacteria and dermatophytes were carried out to identify the aetiological agent. Skin scrapings showed that lesions appearing on the seals were caused by an infestation of Demodex mites, which is uncommon in marine mammals, and were not due to other causative agents (parasites, bacteria or dermatophytes). Treatment with amitraz $(0.01 \%)$ once a week for three weeks and with ampicillin (10 mg/kg SID per os) for six days eliminated the mites and resolved the clinical signs of demodectic mange in the harbour seals. The purpose of this report is to describe the successful treatment of naturally acquired demodectic mange with amitraz in harbour seals.
\end{abstract}

Key words: Phoca vitulina, demodicosis, harbour seal, mite infestation, zoo

Demodex mites (Acarina: Demodecidae) live in the hair follicles and sebaceous glands of a wide range of mammals, including humans (Taylor et al., 2007). These mites have elongated and tapered bodies (0.2-0.4 mm long) with eight very short legs (Taylor et al., 2007; Eo et al., 2010). While Demodex mites are normal inhabitants of the skin, their presence may lead to erythema, alopecia, scaling and dermatitis under altered immunocompetence, especially immunosuppression (Eo et al., 2010; Kuznetsova et al., 2012a). If chronic generalised demodicosis develops, resolution without treatment is unlikely (Fourie et al., 2007). Furthermore, demodectic infestation can act as a predisposing factor for secondary bacterial infections, which may lead to furunculosis and cellulitis (Kuznetsova et al., 2012a), and this is the situation in aquatic animals as well.

*Corresponding author; E-mail: dmkwak@knu.ac.kr; Phone: 0082 (53) 950-7794; Fax: 0082 (53) 950-5955 
Cases of demodicosis have been reported in numerous species of terrestrial mammals (Taylor et al., 2007). Demodex species have also been reported in two marine mammal species including the California sea lion (Zalophus californianus) and the harbour seal (Phoca vitulina) (Dailey and Nutting, 1980; Desch et al., 2003). To our knowledge, no previous study focusing on the treatment of demodectic mange in marine mammals has been conducted, and there is no documented treatment regimen for mange in marine mammals.

\section{History}

Two male harbour seals (Phoca vitulina; 33 and 35 years old, respectively), housed since 2002 at a zoo for exhibition purposes, developed severe, multifocal and diffuse skin lesions (Fig. 1). The lesions were characterised by many circular areas of pyoderma, erosion, nodule, erythema and haemorrhage (Fig. 1A-C). The animals were kept in an enclosed pool without contact to other animals and fed mackerel, pollock and squid.

\section{Clinical examination and treatment}

To identify the aetiological agent (parasites, bacteria or dermatophytes) from the skin lesions, skin scrapings and microscopy for parasites as well as pure cultures for bacteria and dermatophytes were carried out. Skin scrapings were performed superficially three times at a week's interval. The procedures were as follow: lesions were scraped with a scalpel, then the sample recovered from skin scrapings was submitted to a veterinary laboratory for identification. Following treatment of the sample with $10 \%$ potassium hydroxide solution, infestation of Demodex mites was established by microscopy with one to four adults per field in the absence of eggs or larvae. The mites were eight-legged with elongated and tapered bodies, 200-300 $\mu \mathrm{m}$ in length (Fig. 1D).

For the identification of bacteria, the skin scrapings sample was subjected to aerobic culture on blood and MacConkey's agar at $37^{\circ} \mathrm{C}$ for $12-18 \mathrm{~h}$. Pure bacterial cultures from the colonies grown on both types of agar plates were isolated following incubation. Gram-positive and Gram-negative bacteria were observed by Gram staining. The isolated microorganisms were identified as Aeromonas sobria and Streptococcus group L using API biochemical identification kits (bioMérieux, France). In addition, skin scrapings from the lesion were treated with lactophenol to detect a possible presence of fungal elements and then cultured on Sabouraud dextrose agar (Difco Laboratories, USA) (Kim et al., $2015 b$ ) since dermatophytes, including three genera (Epidermophyton, Microsporum and Trichophyton) of fungi, can cause the skin lesions (Nam et al., 2013). However, no fungal agent was detected from the lesions. 

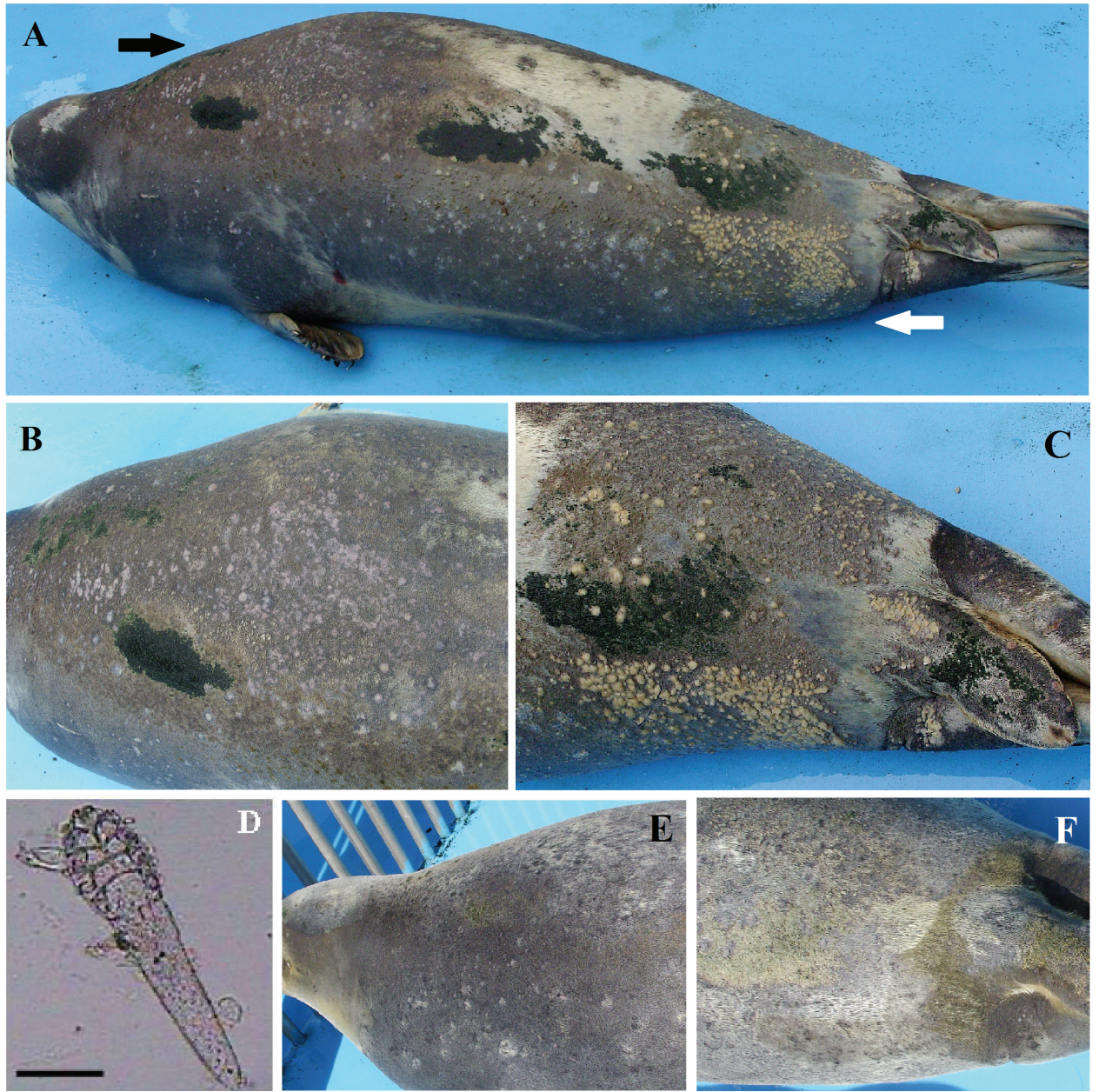

Fig. 1. Two male harbour seals (Phoca vitulina; 33 and 35 years old, respectively), housed since 2002 at a zoo for exhibition purposes, developed severe, multifocal and diffuse skin lesions. $A$. The lesions were characterised by many circular areas of pyoderma, erosion, nodule, erythema and haemorrhage. $B$. Local erosion and erythema with pyoderma indicated by a black arrow in panel A. $C$. A magnified image of pyoderma indicated by a white arrow in panel A. $D$. Infestation with $D e-$ modex sp. was diagnosed based on microscopic analysis of scrapings from skin lesions of the affected harbour seal. The isolated mites had elongated and tapered bodies, 200-300 $\mu \mathrm{m}$ in length and eight stumpy legs at the front of the body. Scale bar $=50 \mu \mathrm{m} . E-F$. Appearance of the harbour seal after the Demodex infestation was eliminated by treatment with amitraz $(0.01 \%)$ and ampicillin $(10 \mathrm{mg} / \mathrm{kg}$, per os, SID) for three times at a week's interval

Once the diagnosis was made, the animals were topically sprayed once a week with amitraz $(0.01 \%$; Greentix, Green Cross, Korea) for a total of three weeks. Amitraz was applied while the animals were out of the water for a minimum of $30 \mathrm{~min}$ before the seals were allowed to re-enter the pool. Ampicillin 
(10 mg/kg, per os, SID; Ampicillin Cap. 500 mg, Chong Kun Dang Pharm., Korea) was also administered for six days to treat deep pyoderma in the skin of the harbour seals and to relieve the bacterial infection. The skin nodules and inflammatory erosion disappeared within three weeks following treatment with both agents (Fig. 1E-F). After one month, follow-up skin scrapings from the lesion sites were negative for Demodex mites after therapy had been completed.

\section{Discussion}

Mites in the genus Demodex are part of the normal flora on the skin of many species of healthy animals (Jones et al., 1997). However, their presence may lead to disease under immunocompromised conditions including old age, stress and abnormal environment (Jones et al., 1997; Taylor et al., 2007; Eo et al., 2010). In the present case, a 33-year-old and a 35-year-old male harbour seal, housed for exhibition at a zoo, developed severe, multifocal and diffuse skin lesions. To the authors' knowledge, there is no known predisposing factor in association with demodicosis in aquatic animals. Various factors such as their advanced age, captivity and stress from exhibition at a zoo could have contributed to their decreased resistance to Demodex infestation and subsequent development of clinical symptoms (Jones et al., 1997).

Although Demodex species are known to infest various species of mammals, these parasites have relatively limited host specificity (Taylor et al., 2007). Demodex species that infest marine mammals have been reported to be distinct from those found on terrestrial mammals (Desch et al., 2003; Kuznetsova et al., $2012 b$ ). The first demodicid isolated from a marine mammal was D. zalophi inhabiting the skin of California sea lions (Zalophus californianus) (Desch et al., 2003). Demodex zalophi is very similar to $D$. canis but has morphologically distinct opisthosoma, ova and genitalia (Desch et al., 2003). Another species, $D$. phocidi, was found on a captive Atlantic harbour seal from Alaska and is morphologically similar to D. brevis from humans (Desch et al., 2003). It is suspected that infestation by $D$. phocidi in harbour seals is associated with persistent hyperkeratosis (Desch et al., 2003), but treatment for this condition has not been previously described and there is no known treatment regimen for mange. In the current study, demodicid mites were successfully eliminated with amitraz in harbour seals.

In addition, Aeromonas sobria and Streptococcus group L were isolated from the skin lesions of the harbour seals. These bacteria cause opportunistic infection when hosts are immunocompromised. Aeromonas spp. are normally found in the aquatic environment (Quinn et al., 2011a), and Streptococcus spp. are commensals on the mucous membranes of animals (Quinn et al., 2011b). Also, these bacteria were isolated from various sources (e.g. watering facility, 
pond water and animals) at the studied zoo in our previous study (Kim et al., 2015a). These species of bacteria commonly infect the skin through exposure to contaminated water or soil, but, typically, are not directly associated with the formation of skin lesions (Kelly et al., 1993; Vally et al., 2004). Thus, the authors believe that demodicosis occurred primarily and the secondary bacterial infection developed through lesions associated with demodicid mites. Therefore, treatment was focused on demodicosis since pyoderma cannot be treated until mites are eliminated (Miller et al., 2013).

The effectiveness of amitraz for eradicating a naturally acquired infestation of Demodex mites was demonstrated here in harbour seals as well as in domestic animals (Folz et al., 1984; Folz et al., 1985; Baynes, 2009). The harbour seals were treated three times weekly with amitraz. This regimen was easily manageable and less stressful compared to treatment with drugs that have to be taken orally. No adverse effects due to the amitraz treatment were observed. However, since amitraz could be toxic to humans and zooplankton cladocerans (Baynes, 2009; Sánchez-Bayo, 2012), it should be handled by people who wear appropriate personal protection. In addition, to avoid contamination of other aquatic organisms, amitraz should be used in confined environments. We also administered ampicillin that relieved deep pyoderma in the skin of the affected animals. It is known that secondary pyoderma frequently accompanies this form of generalised demodicosis (Folz et al., 1985). A previous study showed that systemic treatment with antibiotics alone does not ameliorate persistent demodicosis or demodicid infestation (Kuznetsova et al., 2012a).

Our results indicated that the mites in harbour seals were eliminated by treatment with amitraz. In conclusion, the findings described in this report suggest that amitraz is applicable and effective for treating naturally acquired demodicid infestation in harbour seals.

\section{References}

Baynes, R. E. (2009): Ectoparasiticides. In: Riviere, J. E. and Papich, M. G. (eds) Veterinary Pharmacology \& Therapeutics. Wiley-Blackwell, Iowa, USA. pp. 1181-1201.

Dailey, M. D. and Nutting, W. B. (1980): Demodex zalophi sp. nov. (Acari: Demodicidae) from Zalophus californianus, the California sea lion. Acarologia 21, 423-428.

Desch, C. E., Dailey, M. D. and Tuomi, P. (2003): Description of a hair follicle mite (Acari: Demodecidae) parasitic in the earless seal family Phocidae (Mammalia: Carnivora) from the harbor seal Phoca vitulina Linnaeus, 1758. Int. J. Acarol. 29, 231-235.

Eo, K., Kwak, D., Shin, T., Yeo, Y., Jung, K., Kwon, S., Kim, S. and Kwon, O. (2010): Skin lesions associated with Demodex sp. in a llama (Lama peruana). J. Zoo Wildl. Med. 41, $178-180$.

Folz, S. D., Kakuk, T., Henke, C., Rector, D. and Tesar, F. (1984): Clinical evaluation of amitraz as a treatment for canine demodicosis. Vet. Parasitol. 16, 335-341. 
Folz, S., Kratzer, D., Nowakowski, L., Conklin Jr., R. and Rector, D. (1985): Evaluation of a topical treatment, alone and in combination with a detergent, for generalized demodicosis. Vet. Parasitol. 17, 165-172.

Fourie, L. J., Kok, D. J., du Plessis, A. and Rugg, D. (2007): Efficacy of a novel formulation of metaflumizone plus amitraz for the treatment of demodectic mange in dogs. Vet. Parasitol. 150, 268-274.

Jones, T. C., Hunt, R. D. and King, N. W. (1997): The skin and its appendages. In: Jones, T. C., Hunt, R. D. and King, N. W. (eds) Veterinary Pathology. Lippincott Williams \& Wilkins, Maryland, USA. pp. 817-872.

Kelly, K. A., Koehler, J. M. and Ashdown, L. R. (1993): Spectrum of extraintestinal disease due to Aeromonas species in tropical Queensland, Australia. Clin. Infect. Dis. 16, 574-579.

Kim, K. T., Lee, S. H. and Kwak, D. (2015a): Prevalence, biochemical characteristics, and antibiotic susceptibility of aeromonads, vibrios, and plesiomonads isolated from different sources at a zoo. J. Zoo Wildl. Med. 46, 298-305.

Kim, K. T., Lee, S. H. and Kwak, D. (2015b): Trichophyton mentagrophytes infection in an African lion cub (Panthera leo) and transmission to a zookeeper. Korean J. Vet. Res. 55, 1-3.

Kuznetsova, E., Bettenay, S., Nikolaeva, L., Majzoub, M. and Mueller, R. (2012a): Influence of systemic antibiotics on the treatment of dogs with generalized demodicosis. Vet. Parasitol. 188, 148-155.

Kuznetsova, E., Vysokikh, A. and Bourdeau, P. (2012b): First description of demodicosis in 12 galagos (Galago senegalensis). Vet. Dermatol. 23, 61-64.

Miller, W. H., Griffin, C. E., Campbell, K. L. and Muller, G. H. (2013): Parasitic skin disease. In: Miller, W. H., Griffin, C. E., Campbell, K. L. and Muller, G. H. (eds) Muller and Kirk's Small Animal Dermatology. Elsevier, St. Louis, USA. pp. 284-342.

Nam, H. S., Kim, T. Y., Han, S. H. and Hyun, C. (2013): Evaluation of therapeutic efficacy of medical shampoo containing terbinafine hydrochloride and chlorhexidine in dogs with dermatophytosis complicated with bacterial infection. J. Biomed. Res. 14, 154-159.

Quinn, P. J., Markey, B. K., Leonard, F. C., FitzPatrick, E. S., Fanning, S. and Hartigan, P. (2011a): Bacterial species of limited pathogenic significance. In: Quinn, P. J., Markey, B. K., Leonard, F. C., FitzPatrick, E. S., Fanning, S. and Hartigan, P. (eds) Veterinary Microbiology and Microbial Disease. Wiley-Blackwell, Oxford, UK. pp. 405-410.

Quinn, P. J., Markey, B. K., Leonard, F. C., FitzPatrick, E. S., Fanning, S. and Hartigan, P. (2011b): Streptococci. In: Quinn, P. J., Markey, B. K., Leonard, F. C., FitzPatrick, E. S., Fanning, S. and Hartigan, P. (eds) Veterinary Microbiology and Microbial Disease. WileyBlackwell, Oxford, UK. pp. 188-195.

Sánchez-Bayo, F. (2012): Insecticides mode of action in relation to their toxicity to non-target organisms. J. Environment. Analytic. Toxicol. S4:002. DOI: 10.4172/2161-0525.S4-002.

Taylor, M. A., Coop, R. L. and Wall, R. L. (2007): Parasites of cattle. In: Taylor, M. A., Coop, R. L. and Wall, R. L. (eds) Veterinary Parasitology. Blackwell, Oxford, UK. pp. 51-151.

Vally, H., Whittle, A., Cameron, S., Dowse, G. K. and Watson, T. (2004): Outbreak of Aeromonas hydrophila wound infections associated with mud football. Clin. Infect. Dis. 38, 1084-1089. 